\title{
Study of Influence of Copolymer Vinyl Chloride and Vinyl Acetate on the Properties of Butadiene Nitrile Rubber
}

\author{
Shiraz M. Mammadov ${ }^{1, *}$, Se hrana A. Rzayeva ${ }^{1}$, Adil A. Garibov ${ }^{1}$, Oktay N. Akpe rov ${ }^{2}$, \\ Tunzala F. Gojayeva ${ }^{2}$, Jovdat S. Mammadov ${ }^{1}$, Nus haba M. Hajiyeva ${ }^{1}$ \\ ${ }^{1}$ Institute of Radiation Problems of ANAS, Baku, AZ1143, Azerbaijan \\ ${ }^{2}$ Baku State University, Baku, AZ 1143, Azerbaijan
}

\begin{abstract}
Influence of a copolymer of vinyl chloride and vinyl acetate to the properties of butadiene nitrile rubber has been studied. It is shown that the growth of the molecular weight of BNR by mixing latex rubber and copolymer in a ratio $80: 20,75: 25,65: 35$ leads to obtaining micro heterogeneous systems. Copoly mer in itially acts as an interstructural amp lifier and then depending on their ratio plays the role of the dispersed phase in the plasticization. By the method of rheological analysis it was found out that increase of molecular weight was observed in the interval time (0-90 min), characteristic viscosity increases with the ratio of 75:25 copoly mer from 0.6 to 1.4. A sol-gel analysis showed that with increase in the concentration of the copolymer in BNR the number of chains grid $(1 / \mathrm{Ms})$ in the rubber decreases. It was found out that consumption of cross linked molecules (1/Mn) for the cross-linking is reduced, it becomes constant at a ratio of 100:65:25. Comparis on of the kinetics of thermo metallic oxide vulcanization of BNR with the accelerator disulphide chloride benzene (DSCB) increases the yield concentration of the effective cross-links (n `c) in the molecule BNR. Experiment showed that in the presence of the accelerator DSCB and zinc oxide the structuring main ly goes by the double bond.
\end{abstract}

Keywords Butadiene Nitrile Rubber, Vinyl Chloride, Vinyl Acetate, Viscosity, Rheology, Vulcanization, Spectroscopy

\section{Introduction}

It is known[1-10], that the vinyl compounds containing active and polar groups interact strongly with the hydrocarbon molecular part of poly mer. The structuring of elastomers is observed in the presence of compounds containing two or more active halogen atom and acetate, thus it is possible to obtain sufficiently strong elastomeric materials having a high resistance to the heat ageing, abrasion and dynamic endurance[11-17]. The study of occurring at the same chemical reaction makes it possible to facilitate significantly the development of cross-linking system for manufacturing materials with predetermined properties.

In the literature[1, 11-22] the large number of various substances are described which promotes acceleration of the chemical reaction in butadiene nitrile elastomers, for example, with polyvinyl chloride (VC). With filling polyvinyl chloride butadiene nitrile rubber (BNR) enhances ozone resistance of elastomer and helps to create a solid structure and to form ozone protective film on its surface.

* Corresponding author:

Shiraz_mm55@mail.ru (Shiraz M. Mammadov)

Published online at http://journal.sapub.org/cmaterials

Copyright (C) 2012 Scientific \& Academic Publishing. All Rights Reserved
In the literature[1, 11-22] the large number of various substances are described which promotes acceleration of the chemical reaction in butadiene nitrile elastomers, for example, with polyvinyl chloride (VC). With filling polyvinyl chloride butadiene nitrile rubber (BNR) enhances ozone resistance of elastomer and helps to create a solid structure and to form ozone protective film on its surface.

The systematic researches of the effect of unsaturated elastomers filled with copolymer vinyl chloride with vinyl acetate (VA) to the output parameters of the grid, the changes of the molecular structure, rheological properties and also the content of the double bonds in the polyblend (mixture of elastomer with vinyl chloride and vinyl acetate) was not carried out. It is presented to study the effect of interaction of copoly mer of vinyl chloride with vinyl acetate on the elastic, structural parameters of the grid and rheological properties of butadiene nitrile elastomer.

\section{Experimental}

The butadiene nitrile rubber filled with copoly mer of vinyl chloride with the vinyl acetate is used as an object of research. Filled BNR is obtained during jo int coagulation of butadiene nitrile latex (with the content of the bound acrylonitrile $37-40 \%$ ) with late $x$ of polyvinylchloride (PVC) and poly vinyl acetate (PVA) in the ratio of 80:20, 75:25, 
65:35. According to the research results carried our by IK method -spectroscopy in a butadiene part of poly mer upon polymerization of the is ometric composition of double bonds in the filled system was: 1,2 -isomer of $16 \%, 1,4$-isomer of $18,7 \%$ and trance 1,4 isomer. Macromolecules of SKN-40 rubber consists of statically allocated parts of butadiene, acrylonitrile and filled with vinyl chloride copolymer with the vinyl acetate. Features after the structuring BNR influence to their microstructure, molecular weight, molecular mass distribution (MMR) and gel content. Therefore, before processing researches in filled BNR, number-average and weight-average molecular weight and polydispersity (Mn-69 thousand; Mw-226 thousand; $\mathrm{Mw} / \mathrm{Mn}=4.1)$ has been defined by gel permeation chromatography (GPC) beforehand.

BNR filled with PVC copolymer and (PVA) is expanded in the ratio 75:25, after 15-20 minutes of plasticization the obtained mixture is produced compression of the sample at $143 \mathrm{~K}$ in the range $0-90$ minutes during 20 minutes. For studying kinetic of structuring the 3 mass. part system of disulphonic acid chloride benzene (DSHB) +5 mass. part $\mathrm{ZnO}$ on 100 mass. part of rubber has been used. The characteristic viscosity of BNR filled with copolymer was determined in toluene at $293 \mathrm{~K}$ by known procedures on Ubbelohde type of viscosimeter. The calculation was carried out on Marx Hauvink's equation[ $\eta]=\mathrm{kM} \alpha$ at value of the constant $K=4,9 \cdot 104$ and $\alpha=0,64$ for toluene[23]. Studying elastic formation properties were carried out according to GOST 10722-74. Entrance of concentration of cross-linkage $(\mathrm{n} ' \mathrm{c})$; number of the cross-linked molecules $(1 / \mathrm{Mn} \tau)$ was determined by a sol-gel analysis. The calculation of parameters of a spatial grid of cross-linked elastomer was determined by Flory-Raineri formu la[24]. The change of the molecular structure, filled BNR was determined by IR method of infrared spectroscopy (IRS) in the range of 700-3000c m-1. For this filled BNR was dissolved in toluene during $24 \mathrm{hrs}$. The rubber film was obtained by applying a solution onto a substrate and a constant evaporation of solvent. The boxes of $\mathrm{KBr}$ were used as a substrate during the measurement of spectrum in the range of $600-2000 \mathrm{~cm}$ and the boxes of $\mathrm{LiF}$ and $\mathrm{NaCl}$ in the range of $2000-3000 \mathrm{~cm}$. The substrate with a film was fixed the holder and placed in the sample compartment in the spectrophotometer. Identification of the spectra was carried out in accordance with correlation tables[25-27].

\section{Results and Discussion}

Put forward[7] the colloidal-chemical concept of anomalous growth of viscosity BNR during filling of copolymer vinyl chloride with the vinyl acetate in works is reduced the fact to the following: Fillers (copolymers) are limited compatible with the polymers in the field of the concentration, corresponding to molecular solubility. Copoly mers (vinyl ch loride and vinyl acetate) of the correct reinforcement of rubber increase free volume of polymer, and more, the dense packing of its molecular structure. The increase of a ratio of concentration of copolymer in a polymeric matrix leads to the formation of micro heterogeneous system. Copolymer (filler) first plays a role of the inter structural amplifier, and then the role of fulfilling the disperse phase at plasticization depending on their ratio.

Based on this situation and granting various ratios of filler (copolymer) in BNR, it is necessary to expect:

a) Extremum existence on curve viscosity - a filler ratio only in limited area of temperature test;

b) Dependence of effect of structural changes on transverse strain $\tau$;

c) Dependence of viscosity of the filled rubber on time and temperature of storage of a sample.

Carried-out experimental researches in properties of the butadiene nitrile rubbers (BNR-40) filled with copolymer vinyl chloride and vinyl acetate, confirmed the mentioned assumptions. On figure 1, 2, 3 shown the dependence of elastic characteristics of BNR, filled with copolymer vinyl chloride and vinyl acetate.

One can see that the copolymer chosen in various ratios of copolymer causes change of properties of BNR in plasticity (figure 1), hardness (figure 2) and Mooney viscosity (figure 3). Comparatively observable small growth of plasticity (figure 1) and a decrease of hardness (figure 2) at copolymer ratios 80:20 and 75:25 in BNR lead to change these characteristics on regularities, usual for BNR. According to[1] for mechanical solubility (plastification) to rise in the rate of the gel above $70 \%$ leads to the destruction of chains, which leads to the destruction of the chains that partly different effects on molecular weight and mechanical mechanical processes during the dissolution of the copolymers.



Figure 1. The dependence of plasticity of BNR filled with various ratios of the copolymer of vinyl chloride and vinyl acetate by heating during 90 $\min ; 1-80: 20,2-75: 25,3-65: 35$

Mooney viscosity practically doesn't change at ratios of copolymer 80:20 and $65: 35$ at the duration of structuring within 90 minutes. The structuring BNR with copolymer in ratio of 75:25 was characterized by a higher change of Mooney viscosity after heating.

Studying of the laboratory samples filled with copolymer based on BNR showed that depending on the content of copolymer and duration of time of characteristic viscosity 
monotonously increases in samples and becomes constant and isn't observed increasing of viscosity in samples 1-3 has smaller structuring level.



Figure 2. The dependence of hardness of BNR filled with various ratios of the copolymer of vinyl chloride and vinyl acetate by heating during 90 $\min ; 1-80: 20,2-75: 25,3-65: 35$

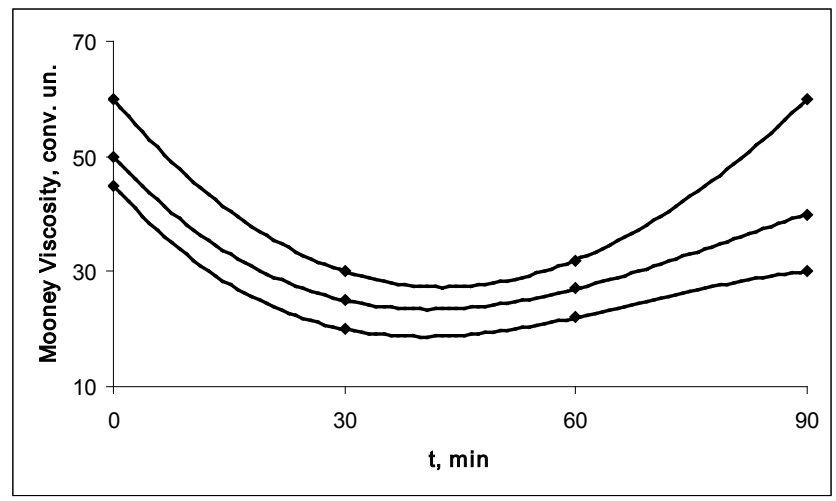

Figure 3. The dependence of viscosity of BNR filled with various ratios of the copolymer of vinyl chloride and vinyl acetate by heating during $90 \mathrm{~min} ; 1$ - 80:20, 2- 75:25, 3- $65: 35$

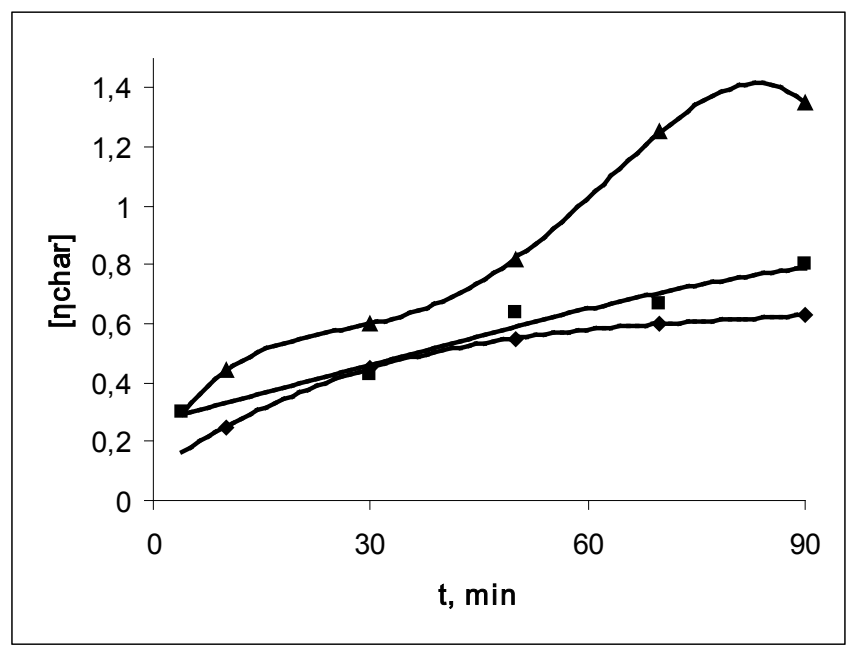

Figure 4. Dependence of the characteristic viscosity of BNR filled with copolymers of vinyl chloride and vinyl acet ate after heating at $423 \mathrm{~K}$ during $90 \mathrm{~min} ; 1-65: 35,2-75: 25,3-80: 20$
The growth of mo lecular weight is observed at duration of structuring at the time interval $0-90 \mathrm{~min}$. The characteristic viscosity increases at samples $2(75: 25)$ with 0.6 to 1.4 . With increase of time the characteristic viscosity (2) becomes constant at 70 minutes, and further reduction of molecular weight is observed at all samples at 120 minutes. BNR is associated with a destruction of main circuit of poly mer.

Viscosity increase in the range of values (0-90min) can be bonded with formation of spatial structures due to reaction of intermolecular cross-lin king (figure 4).

On figure 5 IR-spectra of SKN-40 rubber filled with copolymer vinyl chloride with vinyl acetate 75:25) is presented. The SKN-40 system + copolymer (PVC+PVA) are characterized by polarity, therefore the process of combination SKN-40 with copolymer is main ly defined by polar groups $-\mathrm{C} \equiv \mathrm{N}, \mathrm{C}-\mathrm{Cl}$ and their reactivity at mechanic chemical and thermal influences.

On this basis, the main consideration was given to studying of intensity of the bands of the stretching vibration of the nitrile group, located in areas $2235 \mathrm{~cm}^{-1}$ (figure 5) and being characterized by exceptional stability, both in frequency and form. The intensity of a nitrile band naturally decreases with longer heating from 0 to 90 minutes. For the characteristic of intensity of a nitrile bands were chosen the relative values representing the relation of intensity (or the optical plane) bands $2235 \mathrm{~cm}^{-1}$ to intensity of bands 2925 and $2850 \mathrm{~cm}^{-1}$, corresponding to dissymmetric and symmetric stretching vibrations of commun ications $\mathrm{C}-\mathrm{H}$ of $\mathrm{CH}_{2}$ group. (Figure 5 the bands are not specified).

The most significant changes was observed in the IR spectrum of the sample in the final state, it should be noted decrease in intensity of the band $675 \mathrm{~cm}^{-1}$, observed in the form of a doublet with a band $688 \mathrm{~cm}^{-1}$ in a range of an initial sample and corresponding to stretching vibrations of $\mathrm{C}-\mathrm{Cl}$ communication should be noted.

The band at $1730 \mathrm{~cm}^{-1}$, being observed in IR spectra of the sample in both original, and final states, corresponds to $\mathrm{C}=\mathrm{COC}(\mathrm{C})=\mathrm{O}$ group[25-27]. It is known that, with introduction of fillers into polymer the chemical interaction at the interface of two phases is possible between polymer and fillers $[1,28]$.

The filling of elastomers is that during insertion into the elastomer (in different ratios) the significant change in the parameters of the grid of elastomer occurs.

By sol-gel analysis was found out that with increase in the ratio of the copoly mers in BNR monotonically increase share of sol-gel fraction (28-35\%), the average number molecular weight $\left(\mathrm{Mn}_{\mathrm{s}}\right.$ by Charlz is $3240-4600$ and the nu mber of chain mesh is 8-14) (table 1).

Represented in Table 1 results show that in the process of structuring the of BNR in the presence of the copolymer at various ratio, spending number of cross-linked mo lecules to form in macromolecule of BNR number of cross-links decreases and becomes constant at ratio of copolymer $100: 65: 35$. 




Figure 5. IR spectra of BNR filled with copolymer of vinyl chloride and vinyl acetate (75:25). After heating for $90 \mathrm{~min}$ at $423 \mathrm{~K}$ - No fillers

---In the presence of a copolymer of vinyl chloride and vinyl acet ate

Table 1. The basic structural parameters of the grid for elastomer SCN-40 filled with copolymer vinyl chloride with vinyl acet ate

\begin{tabular}{|ccccc|}
\hline $\begin{array}{c}\text { Copolymer } \\
\text { ratio, } \%\end{array}$ & $\begin{array}{c}\text { Percentage } \\
\text { sol -fraction, } \\
\%\end{array}$ & $\begin{array}{c}\text { Number- } \\
\text { average } \\
\text { molecular } \\
\text { weight, } \\
\mathrm{Mn}_{\mathrm{s}}\end{array}$ & $\begin{array}{c}\text { Number } \\
\text { of chain } \\
\text { mesh } \\
1 / \mathrm{Mc} \cdot 10^{5}, \\
\mathrm{~mol} / \mathrm{cm}^{3}\end{array}$ & $\begin{array}{c}\text { Number of } \\
\text { cross-linked } \\
\text { molecule, } \\
1 / \mathrm{Mn}_{i} \cdot 10^{5}, \\
\mathrm{~mol} / \mathrm{cm}^{3}\end{array}$ \\
\hline $100: 80: 20$ & 28 & 3240 & 8 & 1,8 \\
$100: 75: 25$ & 36 & 4400 & 14 & 1,1 \\
$100: 65: 35$ & 35 & 4600 & 11 & 1,1 \\
\hline
\end{tabular}

BNR significantly differs with greater tendency to cross-linking than other diene rubbers. So it is vulcanized during heating even without the addition of indirect material, and in the presence of disulfide chloride benzene (DCHB) valuable technical vulcanizates can be obtained with participation of zinc oxide.

The system filled of 100 mass. part BNR $(100: 75: 25)+4$ mass. part $\mathrm{DSCB}+5$ mass.part $\mathrm{ZnO}$ was used for vulcanization of filled BNR. The vulcanization was taken in a hydraulic press at $423 \mathrm{~K}$. The duration of vulcanization is 90 minutes.

From the data of table 2 shows that increasing the maximum yield of effective cross-lin ks $n_{c}$ DSCB and metal oxides compared to the thermal vulcanization to the calculation suggest that the presence of reinforcing DSCB and $\mathrm{ZnO}$ vulcanization is mainly on the double bond and the formation of new active sites of metal oxides is suppressed or products their transformation.
Table 2. Limiting energy of activation and level of cross-linking at vulcanizat ion of filled BNR (100:75:25)

\begin{tabular}{|c|ccccccc|}
\hline \multirow{2}{*}{$\begin{array}{c}\text { Cross-linking } \\
\text { agents, } \\
\text { mass.p per } \\
100 \text { mass.p. } \\
\text { rubber }\end{array}$} & \multicolumn{3}{|c|}{$\mathrm{E}, \mathrm{ccal} / \mathrm{mol}$} & \multicolumn{4}{c|}{$\mathrm{n}_{\mathrm{c}} \cdot 10^{-19}, \mathrm{~cm}^{-3}$} \\
\cline { 2 - 7 } & \multicolumn{3}{|c|}{ intervals of time, min } & intervalsoftime, $\mathrm{min}$ \\
\hline $\begin{array}{c}\text { thermal } \\
\text { vulcanization }\end{array}$ & 13,6 & 60 & 90 & 30 & 60 & 90 \\
4 DSCB+ 5 ZnO & 19,8 & 24,1 & 29,3 & 3,9 & 5,6 & 7,8 \\
\hline
\end{tabular}

Comparison of the structural features of the parameters of the grid with their staple rheology, plastic and vulcanizing properties suggests that when combining BNR is a copolymer of $\mathrm{VC}$ and $\mathrm{VA}$ copolymers with increasing content of the destructive processes are observed. The best bed-elastic properties when the content of the copolymer has in the redistribution of 75:25. With increasing heating time, the rise of cross-links and the number of cross-linked molecules remains constant.

\section{Conclusions}

The present work shows that by mixing of latex BNR and filled vinyl chloride and vinyl acetate in a ratio of 80:20, $75: 25,65: 35$ leads to formation microheterogeneous systems, acting as a dispersed phase in mechanical dissolution (plastification).

It is shown that the shear stress of solubility vinyl chloride 
copolymers and vinyl acetate in the rubber, observed the rise in the rate of the gel $(70 \%)$ of the elastomer system, which leads to the destruction of the chains of BNR. Decreasing of the molecular weight of the polymer mass at a shear stress on the rollers influence differently to the rheological properties such as plasticity (figure 1), hardness (figure 2) and of Mooney viscosity (figure 3).

With duration of the structuring in mode $423 \mathrm{~K} \cdot 90^{\prime}$, in a filled elastomer system observed an increase in molecular weight. Characteristic viscosity is increased in samples 2 (75:25) from 0.6 to 1.4 . With increasing time, the molecular weight of the samples filled copolymers at $70 \mathrm{~min}$ is constant, but then, with increasing time of the process of structuring observed decreasing of molecular weight in all samples.

Filled copolymers of $v$ inyl chloride and vinyl acetate with BNR mainly determined by polar groups $-\mathrm{C} \equiv \mathrm{N}, \mathrm{C}-\mathrm{Cl}$ and their reactivity at mechanical, chemical and thermal influences.

Comparison kinetics of thermo metal oxide vulcanization of BNR with participation of amplifier disulphide chloride benzyl (DSCB) show the increasing of cross links yield ( ${ }^{\prime}{ }_{c}$ ) in the molecule of BNR. By method of sol-gel analysis determined that in the presence of reinforcing DSCB and zinc oxide are primarily structured by a double bond and the formation of new active centres are suppressed by metal oxides or the products of their transformation.

\section{REFERENCES}

[1] Mamedov S.M., Yadreev F.I., Rivin E.M. Butadiennitrilniye kauchuki I rezini na ikh osnove. B.: 1991 Elm. p.308

[2] Mamedov S.M. Jurn. prikl. khimiyi. 2005. T. 78. vip. 9. p. 1556.

[3] Pliyev T.N., Chugay A.D., Chechin L.E. Zhurn. Visokomol. Soed. TCh.P. no. 11, 1990, p 178

[4] Schastlivaya N.N Mezhikovsky S.M, Lotakeva S.K, Berlin A.A,. Vysokomol.soed. 1988. vol. 12, № 1

[5] Korshak V.V. Tekhnologiy a plastichnikh mass. Khimiya. M. 1982. p25

[6] Mamedov S.M. Kauchuk i rezina. 2009, №3 p.5

[7] Mamedov S.M. Chemical problems. 2006. №4 p. 648
[8] D. Ham. Sopolimerizasiya. M. Khimiya. 1981.p. 399

[9] Yadreev F.I., Nekravtseva V.M, Krymova A.I. zhurn. kauchuk and rezina. 1996 no.5, p. 27

[10] Mamedov S.M., Garibov A.A. Khimiya i khimicheskaya tekhnologiya. 2009.vo. 52, is. 12. p. 93

[11] T. Kleiner. Kautch. Gummi, Kunstst. 1997. Bd 50, N 1 p. 43

[12] Patent 5616279 USA: MKI C 08K 5/40 C08K 5/14

[13] Patent 5326828 USA:MKI C 08C 19/20 C08C 19/22

[14] Patent 5328636 USA:MKI C 08K 5/46

[15] Mammadov S.M. Kauchuk i rezina. 2007, №5 p.5

[16] Stevinson R.S. Kautch. Gummi, Kunstst. 1991. Bd. 44, N5.p 445

[17] O.O. Tuzhik, T.V. Khokhlova, V.A. Lukasik, S.A.Orlov в. Kauchuk i rezina. 2012 №4 p. 30

[18] Hurm M., C. Dubrabska, H. Draizen „Polumeri“ 1995. V16. N5. p202

[19] Patent 120120069 AZE: MKI C08L 9/00, C08L9/02, C08K $3 / 10$

[20] Mammadov S.M. Visokomol. soed.. 1997, V 12 №9 p. 647

[21] S.M. Mammadov, S.A. Rzayeva, A.A. Garibov et al. American J. of Polym. Sci. 2012, 2(5): 122-128 DOI: 10.5923/j.ajps.20120205.07

[22] S.M.Mamedov, A.A.Garibov, S.A. Rzayeva, J.S.M ammadov, 9th Ukrainian with international participation Scientific Conference "Elastomers: materials, technology, equipment and products "24-28september 2012 Dnepropetrovsk, Ukraine

[23] Kuznetsov E.V., Divgun S.M., Budarina S.M., Budarina L.A. i dr. Praktikum po khimii I fiziki polimerov. M.: Khimiya, 1977. p. 380

[24] Flori P., Rehuian İ.İ. // Chem. Phys. 1948, №11.p. 512

[25] Bellami L.J. The Infrared Spectra of Complex Molecules, vol. $1,1963$.

[26] Nelson K.B. Kolebatelniye spektri I molekularniye protsessi v kauchukakh: Sb. tr. VNIISK. L.: Khimiya, 1970. p. 150

[27] Bakhishev N.G. Spektroskopiya mejmolekularnikh vzaimodey stviy. L.: Nauka. 1982. p. 305.

[28] Richardson M.O. Polymer Engineering Composites. App. Sci. Publ. Ltd. 1979. London 